BOOSTER TUNE CONTROL LIMITS AT HIGH FIELD

BOOSTER TECHNICAL NOTE

NO. 220

C. J. GARDNER and W. van ASSELT

February 10, 1993

ALTERNATING GRADIENT SYNCHROTRON DEPARTMENT BROOKHAVEN NATIONAL LABORATORY

UPTON, NEW YORK 11973 


\title{
Booster Tune Control Limits at High Field
}

\author{
C. J. Gardner and W. van Asselt \\ February 8, 1993
}

The Booster tunes are controlled by excitation of the one-turn (pancake) auxiliary windings located on each of the 48 ring quadrupoles. The windings on the horizontal quads are connected together in series, as are those on the vertical quads, to form two series strings which are powered by two $700 \mathrm{~A}$ bipolar power supplies. The five-turn main windings on the quadrupoles are connected in series with the ring dipoles.

At high field, the quadrupole iron begins to saturate before the dipole iron, which weakens the strength of the quadrupole relative to the dipole and decreases the machine tunes. Measurements reported in Refs. 1-2 show that the quadrupoles begin to saturate when the current in the main windings reaches $2500 \mathrm{~A}$. (The dipole field at this current is $0.6 \mathrm{~T}$ and the magnetic rigidity is $8.3 \mathrm{~T}-\mathrm{M}$.) Using the measured quadrupole strengths, the tunes for various quadrupole currents have been calculated with the MAD program, as discussed in Ref. 3, and the results have been incorporated into the Booster Tune Control program. This program is used to control the tunes throughout the machine cycle and is described in Ref. 4. It calculates and displays the currents required in the horizontal and vertical quadrupole strings for the tunes desired during the cycle, and also calculates the tunes for given currents.

The Booster operates in the region of tune space for which the horizontal and vertical tunes are between four and five. Figures 1 and 2 are tune diagrams showing the second and third order resonances which cross this region. The dashed lines in the figures mark the boundries, obtained from the Tune Control program, of regions that can be reached by adjusting the currents in the horizontal and vertical quadrupole strings. The three diamond shaped regions shown in figure 1 are those that can be reached when the magnetic rigidity is $12.5,14.1$, and $16.0 \mathrm{~T}-\mathrm{M}$, assumming the maximum current available from the power supplies is $\pm 700 \mathrm{~A}$. The 
corresponding regions shown in figure 2 are those that can be reached assumming the maximum current is $\pm 950 \mathrm{~A}$.

For magnetic rigidities of $16.0 \mathrm{~T}-\mathrm{M}$ or greater, the area in which the tunes can be maneuvered is rather limited with the present $700 \mathrm{~A}$ power supplies. If, for example, one wishes to keep both tunes at 4.4 throughout the acceleration cycle, as may be desired for the acceleration of heavy ions, then the present power supplies do not provide quite enough current. Moreover, if one wishes to do third integer resonant extraction, as required for the proposed Booster Application Facility, then extraction on the 13/3 or $14 / 3$ resonance is just barely possible for a rigidity of $16.0 \mathrm{~T}-\mathrm{M}$. Figure 2 shows that these limitations can be overcome if the maximum available current is increased to $\pm 950 \mathrm{~A}$. Such an increase would require increasing the current carrying capacity of the horizontal and vertical quadrupole strings.

\section{REFERENCES}

1. E. Bleser, 'Booster Short Quadrupole Production Measurements', Booster Tech. Note No. 174, Sept. 12, 1990

2. E. Bleser, 'Booster Long Quadrupole Production Measurements', Booster Tech. Note No. 176, Sept. 13, 1990

3. A. Luccio, 'Algorithm and Charts to Calculate and Modify Tunes and Chromaticity in the AGS Booster, Proton Case', Booster Tech. Note No. 179, October 17, 1990.

4. W. van Asselt, 'Booster Tune Control', AGS/AD/Op. Note No. 40, February 4, 1993. 
VERTICAL TUNE

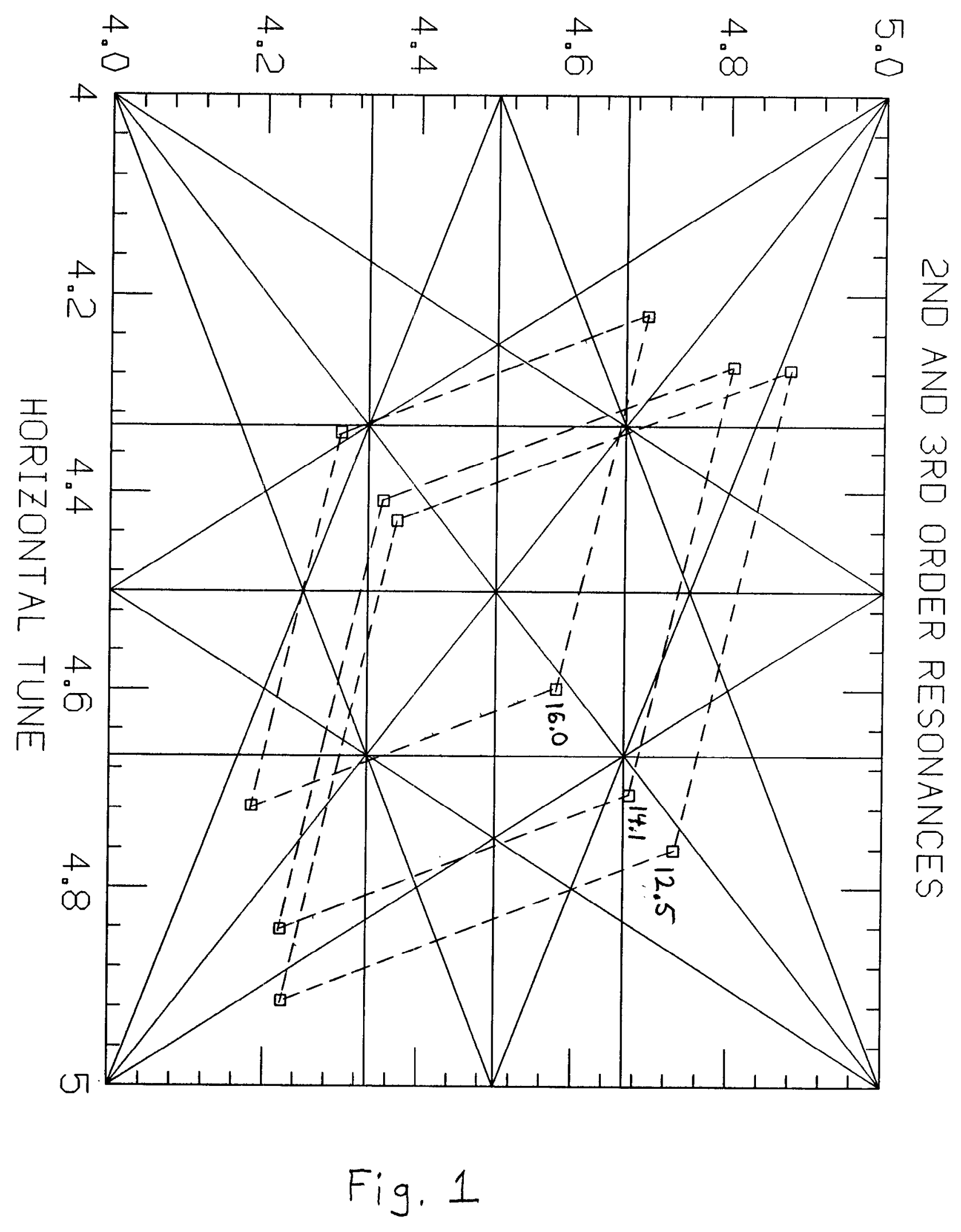


VERTICAL TUNE

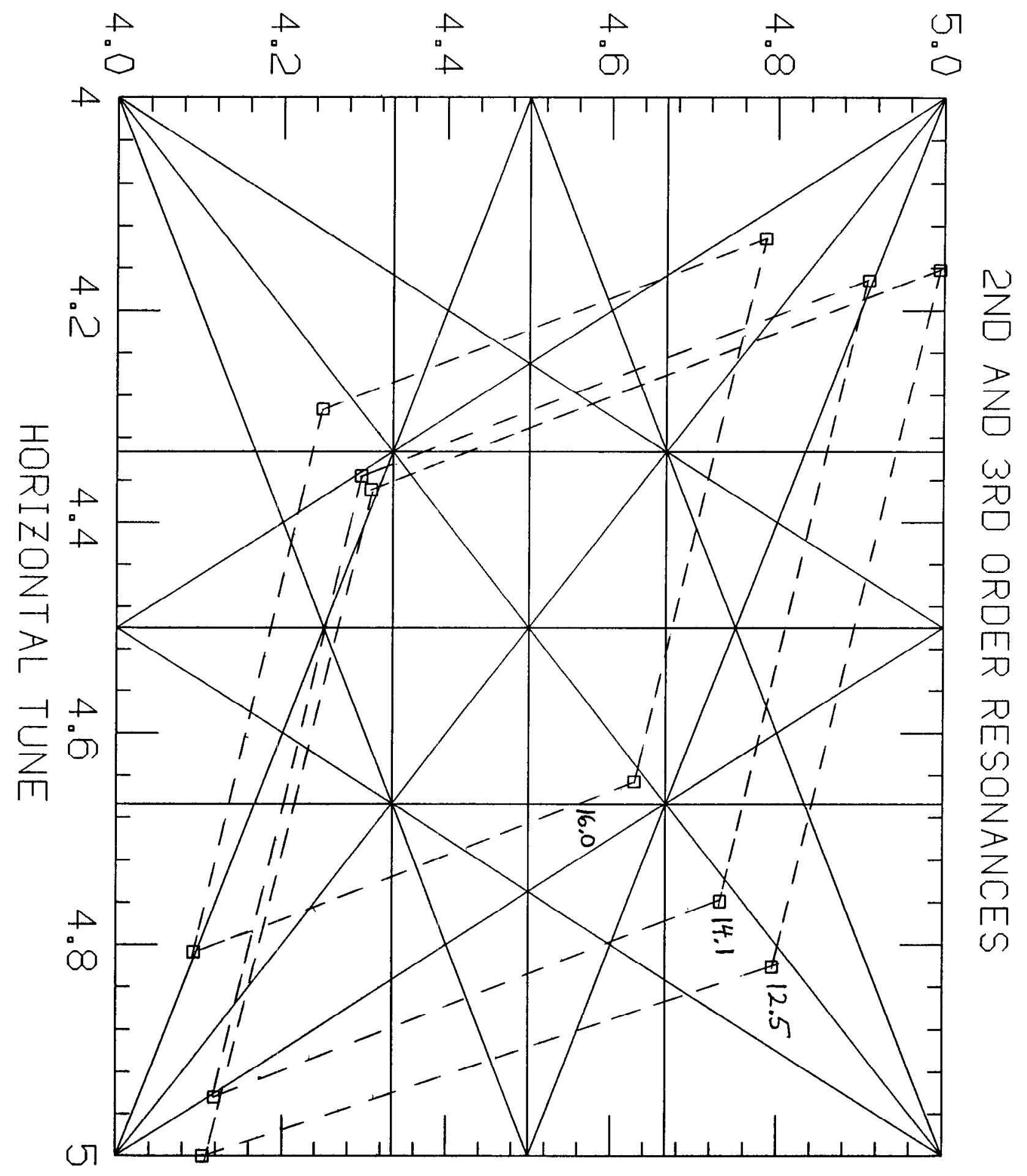

Fig. 2 